\title{
Academic Involvement in Doctoral Education: Predictive Value of Faculty Mentorship and Intellectual Community on Doctoral Education Outcomes
}

\author{
Baaska Anderson \\ University of Liverpool, \\ Liverpool, UK
}

Baaska.anderson@gmail.com

\author{
Marc Cutright \\ University of North Texas, \\ Denton, TX, USA \\ Marc.cutright@unt.edu
}

\section{Stoerm Anderson \\ Walden University, Minneapolis, MN, USA \\ Stoerm.anderson@waldenu.edu}

\begin{abstract}
This study examined doctoral students' perceptions of importance of academic involvement, the frequency of experience with academic involvement in doctoral education, and the relationship between perceived frequency of academic involvement and key doctoral educational outcomes. Using Astin's theory of involvement and the body of literature on doctoral signature pedagogies as conceptual guides, a survey instrument was developed, pilot-tested, and validated with doctoral candidates at three universities in the USA. The constructs faculty mentorship and intellectual community were operationalized and measured using ten items each; participants were asked to indicate the frequency of their experience with, and the importance of, mentorship and intellectual community in their doctoral education experience. Educational outcomes including satisfaction, self-efficacy as scholars, scholarly productivity, and time-to-candidacy were also measured. Data from 217 respondents were analyzed using multivariate statistics, with results suggesting that participants perceived faculty mentorship and intellectual community as very important aspects of doctoral education. Participants' perceived experience with academic involvement strongly predicted doctoral educational outcomes, particularly satisfaction with the doctoral education experience and self-efficacy as scholars, and highlights the importance of academic involvement.
\end{abstract}

Keywords: doctoral education, academic involvement, faculty mentorship, intellectual community, educational outcomes, satisfaction.

Material published as part of this publication, either on-line or in print, is copyrighted by the Informing Science Institute. Permission to make digital or paper copy of part or all of these works for personal or classroom use is granted without fee provided that the copies are not made or distributed for profit or commercial advantage AND that copies 1) bear this notice in full and 2) give the full citation on the first page. It is permissible to abstract these works so long as credit is given. To copy in all other cases or to republish or to post on a server or to redistribute to lists requires specific permission and payment of a fee. Contact Publisher@InformingScience.org to request redistribution permission.

\section{Introduction}

Doctoral education is the backbone of scientific innovation and creativity and is a critical fuel for the global knowledge economy. Having reached the pinnacle of academic achievement, doctoral graduates "understand what is known and discover what is yet unknown" (Shulman, 2008, p. ix) and are expected 
to use that knowledge to provide intellectual leadership to face the challenges of today and tomorrow (Commission on the Future of Graduate Education in the United States, 2010). Envied around the world, doctoral programs in the United States continue to attract the best and brightest from overseas, while doctoral educational practices in the United States continue to serve as a model for other countries (Altbach, 2004; Walker, 2008).

Despite its prominence, doctoral education is not without criticism. Problems such as high attrition, lengthy time-to-degree, and inadequate professional preparation persist as long-term concerns. Doctoral education is also historically the least studied level of formal education; however, that is now beginning to change. Over the past two decades, a push for greater levels of accountability in higher education has stimulated interest in assessing educational effectiveness of doctoral education by measuring desired educational outcomes and identifying factors that promote those outcomes. A burgeoning body of literature and a number of initiatives on doctoral education have emerged over the past two decades reflecting the growing interest and increased attention of scholars in the preparation of the next generation of intellectual leaders.

Organizations such as the Council of Graduate Schools, the Carnegie Foundation for the Advancement of Teaching and Learning, and the Woodrow Wilson Foundation have undertaken projects aimed at improving educational effectiveness of doctoral education. Although problems, purposes, and recommendations of these projects are complex and multifaceted, the quality of students' educational experience as it relates to immediate departments or program communities appears to be a common focal point of the initiatives. In particular, students' interactions with faculty mentors and peers in supportive yet challenging environments along with developmentally meaningful and authentic learning experiences are considered critical to the effective preparation of the next generation of scholars, researchers, and educators (Nyquist, 2002; Walker, 2008; Walker, Golde, Jones, Bueschel, \& Hutchins, 2008). Furthermore, some even propose a Bill of Rights for doctoral students (Schniederjans, 2007).

Although calls for more deliberate, systematic, and structured approaches to doctoral education are increasing in the relevant literature, there is a paucity of evidence that informs the extent to which doctoral programs have implemented emerging recommendations. Similarly, the extent to which doctoral students value such educational practices is yet unknown. Finally, there is little published quantitative research that has explored relationships between factors deemed important in effective doctoral education, particularly research employing multivariate analyses. Those concerned with the effectiveness and efficiency of doctoral programs have limited evidence to draw upon in the further study and improvement of educational experiences and outcomes for doctoral students. There is a need for greater understanding of students' educational experiences and the merit of academic involvement, in the form of intellectual community and mentorship, in promoting desired educational outcomes.

\section{Purposes of the Study}

This study served several purposes. The study first sought to measure the frequency of academic involvement students experienced in doctoral programs and to gauge the perceived importance of such involvement from a student perspective. Relationships between academic involvement and a number of widely accepted doctoral education outcomes were also explored. Doctoral education outcomes included students' self-efficacy as scholars, overall satisfaction with the doctoral education experience, degree progress, and scholarly productivity. Specifically, three questions guided this study:

1. To what extent do doctoral students perceive they experience faculty mentorship and are involved in an intellectual community in their doctoral programs? 
2. How important do doctoral students perceive faculty mentorship and intellectual community to be in their doctoral education experience?

3. What multivariate predictive relationship exists between academic involvement, as conceptualized by mentorship and intellectual community, and doctoral education outcomes?

Identifying the relative value of doctoral students' academic involvement in predicting doctoral educational outcomes may inform research, policy, and practice-oriented communities concerned with the effectiveness of doctoral education. Findings of this study may also serve to guide individual faculty member efforts to improve their own educational practice. Because this study was conducted in the U.S., findings and conclusions may not universally apply to doctoral education in other countries. Exploration of the relationship(s) between academic involvement and doctoral education experiences and outcomes may be a useful starting point in studying the value of intellectual community and mentorship in global contexts.

\section{Guiding Frameworks and Literature}

\section{Theory of Involvement}

This study was informed by Astin's (1984) theory of involvement as an overarching conceptual framework. The concept of involvement refers to the investment of "physical and psychological energy that the student devotes to the academic experience" (p. 297). Astin noted that students learn by becoming involved and that the amount of learning and development in an educational program is "directly proportional to the quality and quantity of student involvement" (p. 298). Educational benefits of undergraduate students' involvement in the academic and social life of college are well documented; involvement is related to multiple dimensions of academic success, including degree completion, satisfaction with educational experience, and social and cognitive growth (Astin, 1993; Pascarella \& Terenzini, 2005, Tinto, 1993).

Involvement theory has been used in research concerning doctoral education as well. Gardner and Barnes (2007), for example, conceptualized doctoral students' engagement in professional organizations relevant to their chosen fields as a form of academic involvement. Of the dimensions of involvement, academic involvement may seem to be more critical in doctoral education than involvement that is more social in nature. However in his discussion on doctoral persistence, Tinto (1993) asserted that academic and social interaction among doctoral program communities is inseparable, in that social interaction with faculty and peers "becomes closely linked not only to one's intellectual development, but also to the development of important skills required for doctoral completion" (p. 232).

Tinto's assertion is supported by Wenger's (1996) observation of learning and learning organization, wherein he concluded that informal social interactions are essential in creativity, problem solving, and knowledge construction where collaboration and context matters. According to Wenger, given the nature of knowledge work, social interaction contributes a "rich resource to learning" (p. 22). The theory of involvement offers a broad lens with which to conceptualize and explore doctoral education experiences and outcomes, benefits of educational programs in yielding student involvement, and resultant student development.

\section{Academic Involvement: Faculty Mentorship and Intellectual Community}

Walker et al. (2008) suggest two broad forms of educational experience relevant to doctoral student learning and development as a scholar: experiential learning of scholarship with seasoned mentors, and participation in a lively community of scholars that exchange ideas, feedback, and 
resources. Experiential learning that "builds in size and complexity" (Walker et al., 2008, p. 65) with mentors who offer deliberate guidance and feedback in social interaction and collaboration promotes doctoral students ability to "think and behave in the culture of the domain" (Brown, Collins, \& Duguid, 1989, p. 40).

Mentorship is a purposeful educative process in which a faculty member deliberately promotes doctoral students' development as a scholar in a one-to-one or group setting, acting as a guide, role model, teacher, and sponsor to the student. Mentorship may involve providing students with opportunities for experiential learning of various forms of scholarship as well as feedback on various aspects of student development as a scholar and guidance in terms of degree completion. Intellectual community, however, involves formal and informal interactions among a broader community within the department or program, including both faculty and students, exchanging ideas and feedback in support of each other's learning and scholarship.

In this study, faculty mentorship and intellectual community are collectively conceptualized as forms of academic involvement in doctoral education. Both forms of academic involvement speak to the inherently collaborative and social nature of knowledge work (Wenger, 1996). As Walker et al. (2008) noted, these two educational experiences intersect in that they both involve the exchange of intellectual resources. It is this interaction within local department or program communities that contextualizes students' educational experiences, often affecting students' decisions to persist or depart from doctoral study (Gardner, 2010; Golde, 2005; Tinto, 1993).

The literature lends support to Walker et al.'s (2008) recommendations, noting the need to provide students with experiential learning that resembles scholar-practitioners' work and life in their chosen field; such learning should occur early on and throughout their programs and be coupled with deliberate and constructive guidance and feedback (Austin, 2009; Boyle \& Boice, 1998; Gardner, 2008; Golde, 2005; Haworth \& Bair, 2000; O’Meara, Knudsen, \& Jones, 2013). Such educational experiences begin to socialize students to the scholarly work expected of them as doctoral students and scholars, easing their transition toward independent scholarship. Early research experiences (Gardner, 2008; Golde, 2005), effective advising and mentoring (Nyquist \& Woodford, 2000), especially relative to student degree progress and performance (Council of Graduate Schools, 2009; Golde \& Dore, 2001; Maher, Ford, \& Thompson, 2004), and development that bridges multiple forms of scholarship and scholarly work (Austin \& McDaniels, 2006) are areas that have been identified as needing improvement in doctoral education.

\section{Doctoral Education Outcomes}

Doctoral education outcomes refer to a set of characteristics, abilities, and achievements doctoral students are intended to achieve or possess. Although multiple doctoral education outcomes have been explored and reported in the literature, degree completion and degree progress have also received significant attention from policy- and practice-oriented communities alike (Council of Graduate Schools, 2009). The following educational outcomes were of interest in this study: selfefficacy, scholarly productivity, satisfaction, and degree progress. Student perceptions of these outcome variables were examined in terms of their relationship with perceived level of academic involvement.

\section{Self-efficacy}

Self-efficacy is the "belief in one's capabilities to organize and execute the courses of action required to produce given attainment" (Bandura, 1997, p. 3), and it affects one's cognitive and motivational functioning and approach to tasks. In doctoral education, students' self-efficacy in research has been explored most frequently (Baltes, Hoffman-Kipp, Lynn, Waltzer-Ward, 2010; Lambie, Hayes, Griffith, Limberg, \& Mullen, 2013). In this study, however, doctoral students' 
self-efficacy in five dimensions of scholarly work were explored: conducting research, publishing, teaching, applying knowledge in novel contexts, and working collaboratively with other scholars.

\section{Scholarly productivity}

Doctoral students' scholarly productivity, in the form of conference presentations and peerreviewed publications, was conceptualized as a relevant educational outcome, as both are integral to the conduct of scholarship (Shulman \& Hutchins, 1998). Doctoral students should graduate with some capacity to share their work with a broader intellectual community (Golde \& Dore, 2001). Furthermore, scholarly productivity is often considered an important educational outcome for doctoral students (Gardner, 2009), and empirical evidence links scholarly productivity with research self-efficacy (Lambie et al., 2013). Furthermore, governing bodies may use similar metrics as a benchmark by which doctoral programs are assessed (Texas Higher Education Coordinating Board, 2009). Scholarly productivity was operationalized as the following two dimensions: the number of papers delivered (or scheduled to deliver) at professional meetings, and the number of peer-reviewed manuscripts published, accepted for publication, or under-review at the time of completing the survey, such as journal articles, book chapters, or book reviews.

\section{Satisfaction}

In an increasingly market-oriented higher education system, overall satisfaction with the doctoral education experience is an important outcome by which doctoral programs will often be judged. Although doctoral students are generally satisfied with their doctoral education experience (Golde \& Dore, 2001), quality and quantity of student interaction with faculty appears to be most significant factor related to satisfaction (Barnes \& Randall, 2011; Lovitts, 2001). This study examined students' overall satisfaction with their doctoral education experience in relation to their perceived degree of academic involvement.

\section{Degree progress}

Given the wide variation among doctoral students in the speed with which they complete their doctoral degrees (Council of Graduate Schools, 2009) and the common use of degree progress as a benchmark with which to evaluate program effectiveness and efficiency, understanding factors related to timely degree progress is of critical importance to doctoral education. Degree progress was operationalized as the number of semesters (i.e., Fall, Spring, and Summer) elapsed between enrollment in the doctoral program and achievement of doctoral candidacy. A variety of factors are associated with degree progress, including financial support, quality of advising and mentoring from faculty, and opportunities for experiential learning (Council of Graduate Schools, 2009). This study examined the extent to which students' perceived level of academic involvement was related to degree progress.

\section{Methods}

\section{Participants}

A convenience sample of doctoral candidates pursuing research doctoral degrees across the disciplines and fields of study at three public higher education institutions in the Southwest United States was used. Doctoral candidates, having completed coursework and passed any applicable examination(s), were completing dissertations in the final stage of doctoral persistence. Doctoral candidates were sampled as they have formally transitioned from being consumers of knowledge to creators of knowledge (Lovitts, 2005), demonstrating competence to make original and substantial contributions to their chosen field (Council of Graduate Schools, 2005). Choosing to 
sample doctoral candidates was not only guided by programmatic turning points in doctoral education, but also in that it captures the unique interpersonal relationships, learning, and development associated with this defining stage of doctoral experience.

Of the three institutions, one is classified as a Research University with high research activity (RU-HRA), while the other two institutions are Doctoral/Research universities (D/RU) (Carnegie Foundation for the Advancement of Teaching, 2010). Historically, all three were teacher education institutions and currently have large undergraduate and master's programs in addition to a broad range of doctoral programs.

Senior administrative staff at the Graduate School in each institution contacted doctoral candidates and requested voluntary participation in the study by distributing an email that contained a web link to the survey to appropriate listservs. An online version of the survey was administered to doctoral candidates in Spring 2011. Two reminders were sent in two-week intervals. Based on estimates of administrative staff responsible for distributing the survey at each institution, approximately 1,400 doctoral candidates with active listserv accounts received the survey. A total of 217 doctoral candidates completed the online survey upon self-selection, representing an overall estimated response rate of $15.5 \%$, with estimated response rates for individual institutions ranging between $14 \%$ and $18 \%$.

\section{Survey Instrument and Variables}

Guided by the literature on doctoral education, a survey instrument was developed to measure variables pertinent to doctoral candidates' perceived academic involvement and doctoral educational outcomes. The construct of academic involvement was represented by two sub-constructs, faculty mentorship and intellectual community, each of which were represented by ten specific indicators. The 20 total indicators of the two constructs were then measured in terms of perceived frequency and perceived importance of such experiences using a 7-point Likert-type scale, with 1 indicating never or not at all important, and 7 indicating very often or very important. Specific indicators of mentorship and intellectual community, as measured in the survey, are presented in Table 1.

A total of nine doctoral education outcomes were measured, including self-efficacy in conducting five different forms of scholarly work, scholarly productivity in terms of the number of conference presentations and peer-reviewed publications authored during doctoral education, satisfaction with the doctoral education experience, and degree progress. Specifically, self-efficacy refers to students' assessment of their educational experiences in terms of preparing them to conduct original research from conception to interpretation of results, to publish research results, to teach disciplinary knowledge to undergraduate students, to apply disciplinary knowledge in addressing problems of practice, and to work collaboratively with other scholars. Given the sample, degree progress was defined and operationalized as time-to-candidacy. This variable was derived from two items that measured the semester students took the first course in pursuit of their current doctoral degree program and the semester that they successfully completed examinations, therefore advancing to doctoral candidacy.

In addition, several other variables were measured to contextualize the findings of this study. These variables include sex, ethnicity, citizenship and/or residency status, age, doctoral and master's degree specialties, and career plans following graduation. The development of the instrument underwent content validation by doctoral faculty and students, and two subsequent stages of pilot testing with doctoral candidates that represent a broad spectrum of disciplines and fields of study, and revised accordingly. 
Table 1: Academic involvement variables: Faculty mentorship and intellectual community

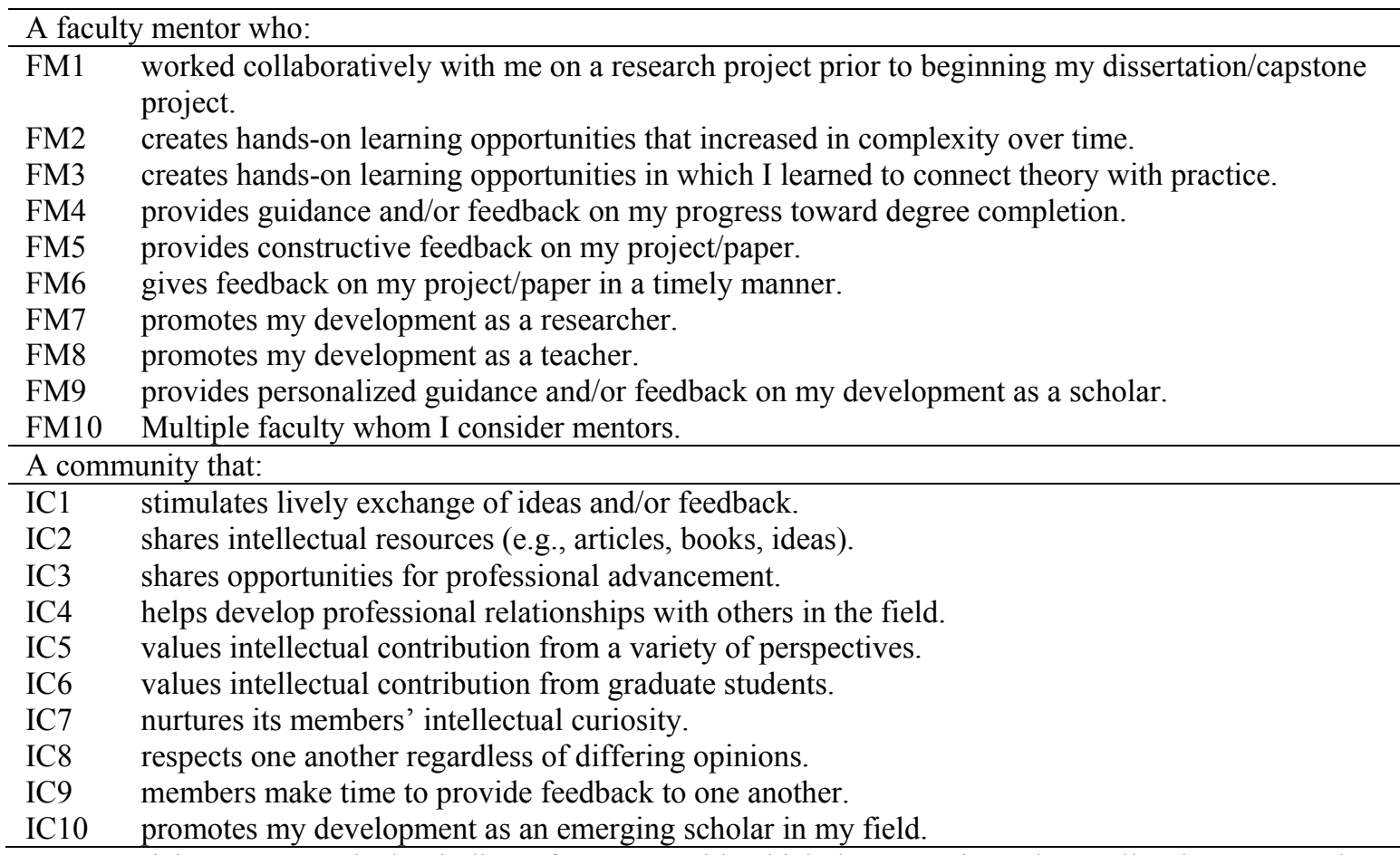

Note. Participants were asked to indicate frequency with which they experienced as well as importance they ascribe to each indicator of faculty mentorship and intellectual community on a 7-point scale $(1=$ Never, Not at all important; $7=$ Very often, Very important).

FM=Faculty mentorship. IC=Intellectual community.

\section{Data Analysis}

Descriptive statistics were used to answer the first two research questions. Canonical correlation and canonical commonality analyses were used to answer the third research question. Canonical correlation analysis (CCA) is a multivariate analysis method that allows assessment of the degree to which two or more continuously scaled variable sets are related to each other and how the specific variables in each variable set contributes to the overall model. In this study, the two variable sets were academic involvement and doctoral education outcomes. CCA creates two composite variables out of the measured variables in the independent and dependent variable sets, then correlates the two composite variables, thus reducing the risk of experimentwise Type I error (Sherry \& Henson, 2005; Thompson, 1991). Following the CCA, a canonical commonality analysis was performed to clarify the nature and the degree of variance each variable contributed in creating the composite variable set, both uniquely and in common with other variables (Nimon, Henson, \& Gates, 2010).

Prior to substantive analyses, data were screened to determine multivariate normality, identify outliers, and detect anomalies such as miscoded or missing data. Psychometric integrity of scores on the 20 observed variables hypothesized to represent two constructs, mentorship and intellectual community, were assessed using Cronbach's $\alpha$ and exploratory factor analysis (EFA). Using the correlation matrix of association, factors were extracted using principal component analysis with oblique (promax, $\mathrm{k}=4$ ) rotation. Given the expected relationship between the two constructs, promax rotation was chosen because it allows factors to be correlated (Thompson, 2004). Factor retention was informed by multiple factor retention test results, including eigenvalue (EV) (Kaiser, 1960), scree test (Cattell, 1966), minimum average partial (MAP) analysis (Velicer, 1976), and parallel analysis (PA). Because an oblique rotation method was used, both factor pattern and 
factor structure coefficients were interpreted in assessing each item's relative representation of associated factors (Henson \& Roberts, 2006).

\section{Results}

\section{Data Screening and Description of the Participants}

Table 2 presents descriptive statistics for variables concerning participants' background characteristics. Of the 217 participants, about half were doctoral candidates at a RU-HRA (53.5\%), while the two D/RUs were approximately equally represented in the remaining half. Of the total sample, $73.7 \%$ of participants identified themselves as female, $65.4 \%$ as white, non-Hispanic, and $85.3 \%$ as U.S. citizens. The data therefore represent a predominantly white, female, and American body of students pursuing research doctoral degrees. Although a variety of disciplines and fields of study were represented in the sample, $53 \%$ were doctoral candidates pursuing a doctorate in the field of education. Additionally, over half of participants (59\%) held some form of graduate assistantship during their doctoral study. Finally, 58.08\% of participants plan to work in either teaching and/or in research capacities, and 79.3\% plan to work in an educational setting.

Table 2: Participants' backgrounds characteristics $(\mathrm{N}=\mathbf{2 1 7})$

\begin{tabular}{|c|c|c|}
\hline Group & $n$ & $\%$ \\
\hline \multicolumn{3}{|l|}{ Institution } \\
\hline Research University -High Research Activity & 116 & 53.5 \\
\hline Doctoral/Research University 1 & 46 & 21.1 \\
\hline Doctoral/Research University 2 & 55 & 25.3 \\
\hline \multicolumn{3}{|l|}{ Sex } \\
\hline Female & 160 & 73.7 \\
\hline Male & 57 & 26.3 \\
\hline \multicolumn{3}{|l|}{ Ethnicity } \\
\hline American Indian/Alaskan Native & 1 & .5 \\
\hline Asian/Asian American/Pacific Islander & 24 & 11.1 \\
\hline Black/African American & 27 & 12.4 \\
\hline Hispanic/Latino & 12 & 5.5 \\
\hline Native Hawaiian/Other Pacific Islander & 0 & 0 \\
\hline Multiracial & 11 & 5.1 \\
\hline White, non-Hispanic & 142 & 65.4 \\
\hline \multicolumn{3}{|l|}{ Citizenship } \\
\hline U.S. Citizen & 185 & 85.3 \\
\hline Permanent resident & 8 & 3.7 \\
\hline Temporary resident & 24 & 11.1 \\
\hline \multicolumn{3}{|l|}{ Doctoral degree specialization } \\
\hline Education & 115 & 53.0 \\
\hline Other & 102 & 47.0 \\
\hline \multicolumn{3}{|l|}{ Doctoral degree type } \\
\hline $\mathrm{PhD}$ & 149 & 68.7 \\
\hline EdD & 67 & 30.9 \\
\hline DBA & 1 & .5 \\
\hline
\end{tabular}




\begin{tabular}{lcc}
\hline Group & $\boldsymbol{n}$ & $\boldsymbol{\%}$ \\
\hline Career plan-primary work & & \\
\hline Post-doc & 23 & 7.59 \\
Teaching & 56 & 18.48 \\
Research & 31 & 10.23 \\
Teaching \& Research & 89 & 29.37 \\
\hline Administration/Management & 51 & 16.83 \\
\hline Independent work & 28 & 9.24 \\
\hline Start private business & 17 & 5.61 \\
Other & 8 & 2.64 \\
Career plan-primary employer & 172 & 79.3 \\
\hline Education sector & 25 & 11.5 \\
Government/Non-profit sector & 13 & 6.0 \\
\hline Business/Industry & 7 & 3.2 \\
\hline Other & & \\
\hline
\end{tabular}

Pursuant to answering the third research question, data related to academic involvement and doctoral education outcomes were screened for multivariate normality and outliers. Multivariate normality was assessed using Thompson's (1990) graphic method. The resultant bivariate relational graphics between $\chi^{2}$ and Mahalanobis distance formed a relatively straight diagonal line, an indication that the assumption of multivariate normality is tenable (Henson, 1999), suggesting a normal distribution of sample data to population parameter.

\section{Psychometric Integrity and Variable Reduction}

Table 3 presents reliability and validity estimates of scores on the 20 observed variables hypothesized to represent doctoral students' perceptions of how frequently they experienced faculty mentorship and intellectual community. Reliability analyses resulted in Cronbach's $\alpha$ coefficients of .94 for faculty mentorship and .95 for intellectual community. These coefficients were unable to be increased by deleting any item and are considered ideal (Loo, 2001) in that they indicate the variables collectively measure their respective construct well (Henson, 2001).

EFA resulted in a two-factor model that explains $68 \%$ of variance in the data, where each factor explains about $35 \%$ and $32 \%$ of the variance prior to rotation. Communality coefficients ranged from .51 to .82 , suggesting that each variable is reasonably well explained across both factors. The factor pattern and factor structure coefficients suggest a clear factor structure where each observed variable distinctly represents its respective construct. The moderate positive relationship between the two constructs $(r=.63, p<.01)$ supports the use of oblique rotation method. Reliability estimates and EFA results suggest psychometric integrity in the scores hypothesized to represent the two constructs, indicating they are reliable and valid measures of faculty mentorship and intellectual community.

Having verified psychometric integrity of the scores, factor scores related to perceived frequency of experience with faculty mentorship and intellectual community were calculated for each participant using Thompson's (1993) method, thereby reducing 20 observed variables to two latent variables. Scores on these two latent variables were then used as independent variables predicting the composite dependent variable, doctoral education outcome, in research question 3. Such variable parsimony helps "improve power against Type II error" (Thompson, 2004, p. 5). 


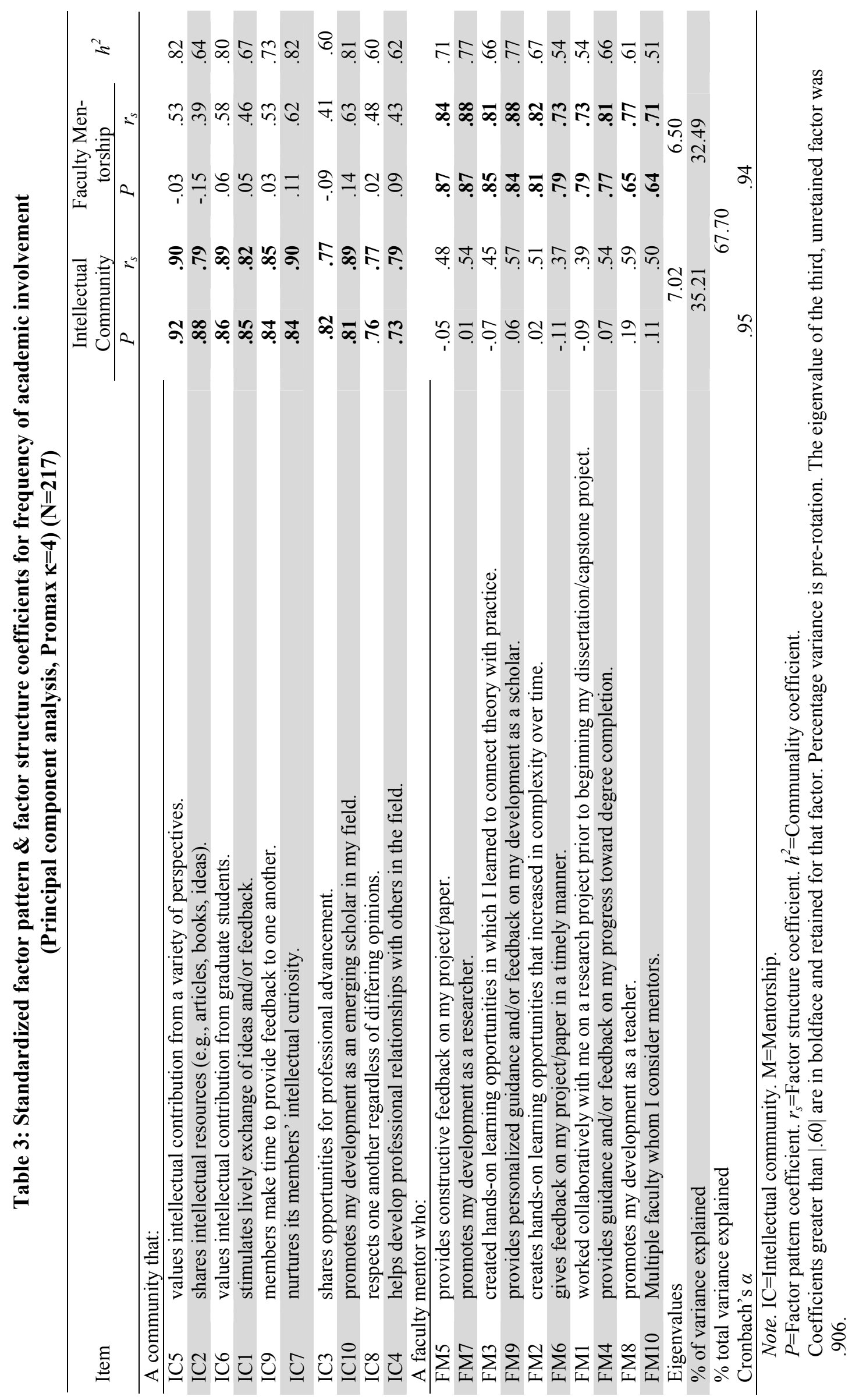




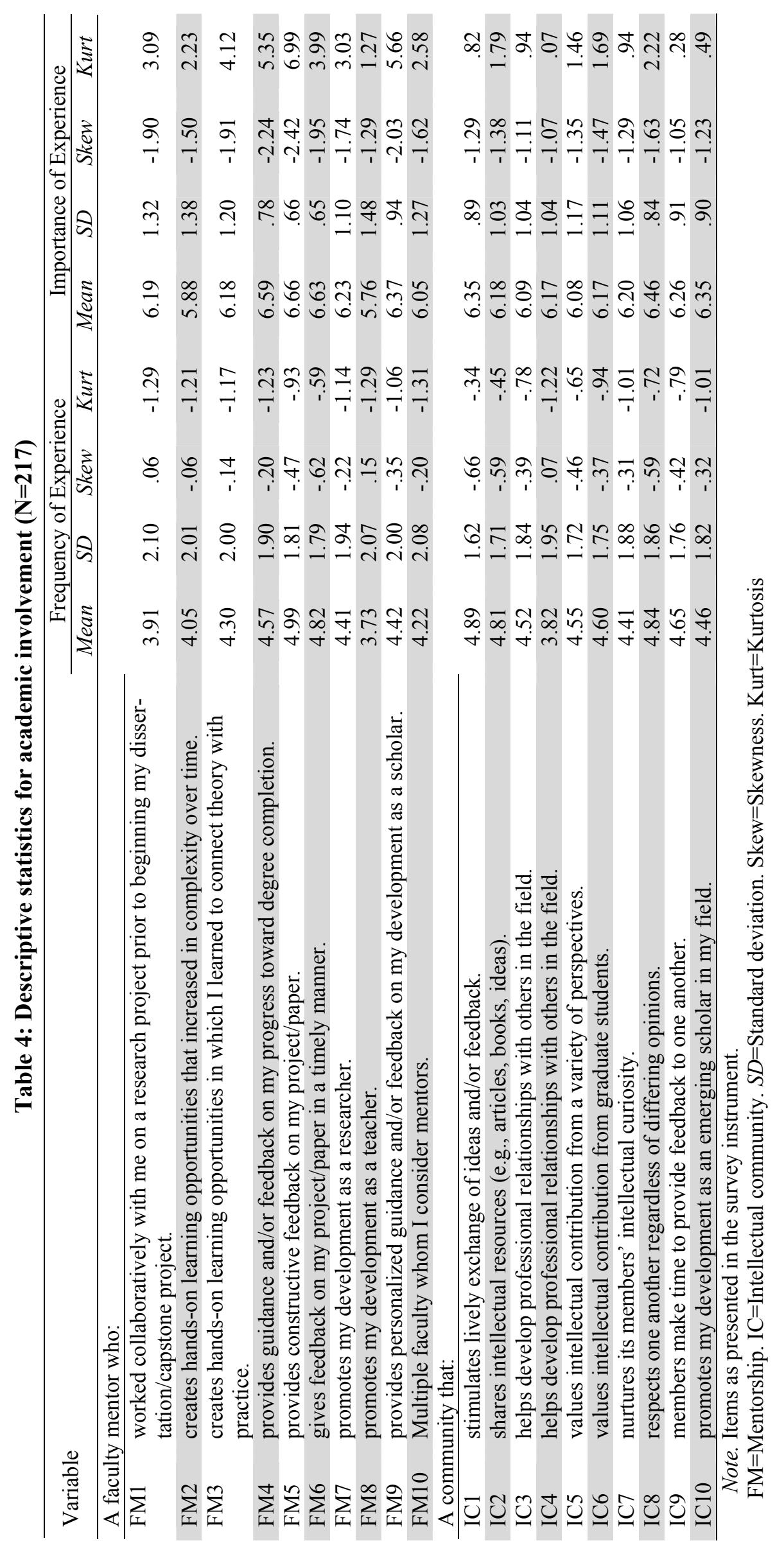




\section{Experience with Faculty Mentorship and Involvement in Intellectual Community}

Descriptive statistics were calculated for the 20 variables representing participants' perceptions of frequency and importance of experience with faculty mentorship and intellectual community to address research questions 1 and 2. Overall, perceived experience of both faculty membership and intellectual community clustered near the midpoint of a seven-point scale ranging from never (1) to very often (7). As presented in Table 4, the mean scores ranged from 3.73 to 4.99 for perceived frequency of experience with faculty mentorship and from 3.82 to 4.89 for perceived frequency of experience with intellectual community.

Of the ten dimensions of faculty mentorship, participants perceived to have experienced a faculty mentor who provided feedback on a paper/project and degree progress more frequently than any other dimension. On the other hand, participants perceived to have experienced a faculty mentor who promoted their development as a teacher and who involved them in pre-dissertation research experience less frequently than any other dimension. Of ten dimensions of intellectual community, participants perceived to have experienced community that exchanged ideas and feedback, shared intellectual resources, and respected one another most frequently, and to have experienced an intellectual community that promoted professional networking least frequently.

Given the variation among responses, frequencies were consulted to further interpret the data. Responses were generally evenly divided between all 7 response choices. This means that a fair number of participants reported to have never experienced one or more dimensions of faculty mentorship or intellectual community. For example, $18 \%$ of participants perceive to have never experienced faculty who promoted their development as a teacher, and $20 \%$ report never having been involved with them in pre-dissertation research. Conversely, only 3\% of participants perceive to have never had faculty who provided constructive and timely feedback on their paper/project and only $4 \%$ report never having received feedback on degree progress. Likewise, a small minority of participants reported never having experienced most dimensions of intellectual community, however $15 \%$ of participants perceive to have never experienced an intellectual community that helps develop professional relationships with others in the field.

\section{Importance of Faculty Mentorship and Intellectual Community}

Mean scores of the 20 variables representing participants' perceived importance ranged from 5.76 to 6.66 for faculty mentorship and from 6.08 to 6.46 for intellectual community, clustering near the upper end of a seven-point scale ranging from not at all important (1) to very important (7). Standard deviation values indicate relative homogeneity among participants' perceptions of importance relative to their perceptions of how frequently they experienced each dimension of faculty mentorship and intellectual community. This is reflected in a leptokurtic distribution that is generally taller and thinner than a normal distribution, indicating that perceived importance of faculty mentorship and intellectual community was more uniform than perceived frequency with which participants experienced the same dimensions.

Of the ten dimensions of faculty mentorship, participants rated having a faculty mentor who provided constructive and timely feedback on their paper/project, as well as having a faculty mentor who provided feedback on their degree progress, as most important among dimensions of faculty mentorship. It is worth nothing that, as mentioned above, these two dimensions were also perceived to be experienced most frequently. On the other hand, mentors who promoted student development as a teacher and offered hands-on learning opportunities that increased in complexity were rated as the least important dimension. Compared to faculty mentorship, all dimensions of intellectual community were more uniformly rated as important. Frequency counts support the relative homogeneity of perceived importance of all 20 dimensions. 


\section{Predictive Relationship between Academic Involvement and Doctoral Education Outcomes}

The final research question examined the multivariate predictive relationship between doctoral students' academic involvement and doctoral education outcomes using two latent variables, faculty mentorship and intellectual community, as predictors of nine measured variables of doctoral education outcomes. Canonical correlation analysis (CCA) was conducted using academic involvement as a predictor of doctoral education outcomes. Canonical commonality analysis was then performed to clarify each variable's unique and shared contributions in the creation of composite variables. Table 5 presents the results of the canonical correlation and canonical commonality analyses.

CCA yielded two functions with $R_{c}^{2}$ of $.552(p<.001), .053(p=.29)$ for each function. Collectively, the full model across two functions was statistically significant using the Wilk's $\lambda=.422$ criterion, $F(18,386)=10.09, p<.001$. Given Wilk's $\lambda$ represents the variance unexplained by the model, $1-\lambda$ yields the full model effect size in an $r^{2}$ metric. The $r^{2}$ effect size was .578 for the two canonical functions, indicating substantial (57.8\%) shared variance between these two variable sets.

Given the statistical and practical significance, the first function was interpreted further to determine the source of effect. Both faculty mentorship and intellectual community made meaningful contributions to the creation of the composite predictor variable for this model, academic involvement, though faculty mentorship contributed more than intellectual community. This conclusion was supported by both the canonical function coefficients, $\beta=-.689$ and $\beta=-.410$, as well as the structure coefficients, $r_{s}=-.948$ and $r_{s}=-.846$.

For the doctoral education outcome variable set, satisfaction with the doctoral education experience (O6) made the largest contribution to the composite dependent variable, doctoral education outcome, followed by all five variables concerning participants' self-efficacy in undertaking scholarly work (O1-O5). This conclusion was supported by both the canonical function and structure coefficients. However, tangible educational outcomes such as number of conference presentations and publications (O7 and $\mathrm{O} 8$ ) and time-to-candidacy (O9) made negligible contributions.

Given that variables $\mathrm{O} 7, \mathrm{O} 8$, and $\mathrm{O} 9$ accounted for near zero variance, $\mathrm{CCA}$ was again performed without $07-09$ in order to obtain a more parsimonious model, resulting in negligible reductions in canonical effect for the full model (Wilk's $\lambda=.444$ ) and for the first function $\left(R_{c}{ }^{2}=.539\right)$.

Similarly, negligible changes were observed in each remaining variable's contribution to the effect. These results suggest that doctoral students' academic involvement strongly predicts educational outcomes such as satisfaction and self-efficacy; however outcomes such as scholarly productivity and time-to-candidacy are not meaningfully related to academic involvement.

Inconsistency between canonical function coefficients and structure coefficients for the first four outcome variables suggests that the creation of the composite outcome variable did not incorporate variance from these four outcome variables. Considering the multicollinearity in this model, canonical commonality analysis was performed to clarify unique and common variances each variable contributed to the model (Nimon et al., 2010). Results indicate that, in the predictor variable set, variance unique to faculty mentorship (.182) yet also common to both faculty mentorship and intellectual community (.303) explains about $92 \%$ of the variance in the composite predictor variable. Faculty mentorship was inarguably the dominant variable in this set. Although the variance accounted for by intellectual community is not insignificant, most of its variance, $57 \%$ out of $65 \%$, was also accounted for by mentorship. 


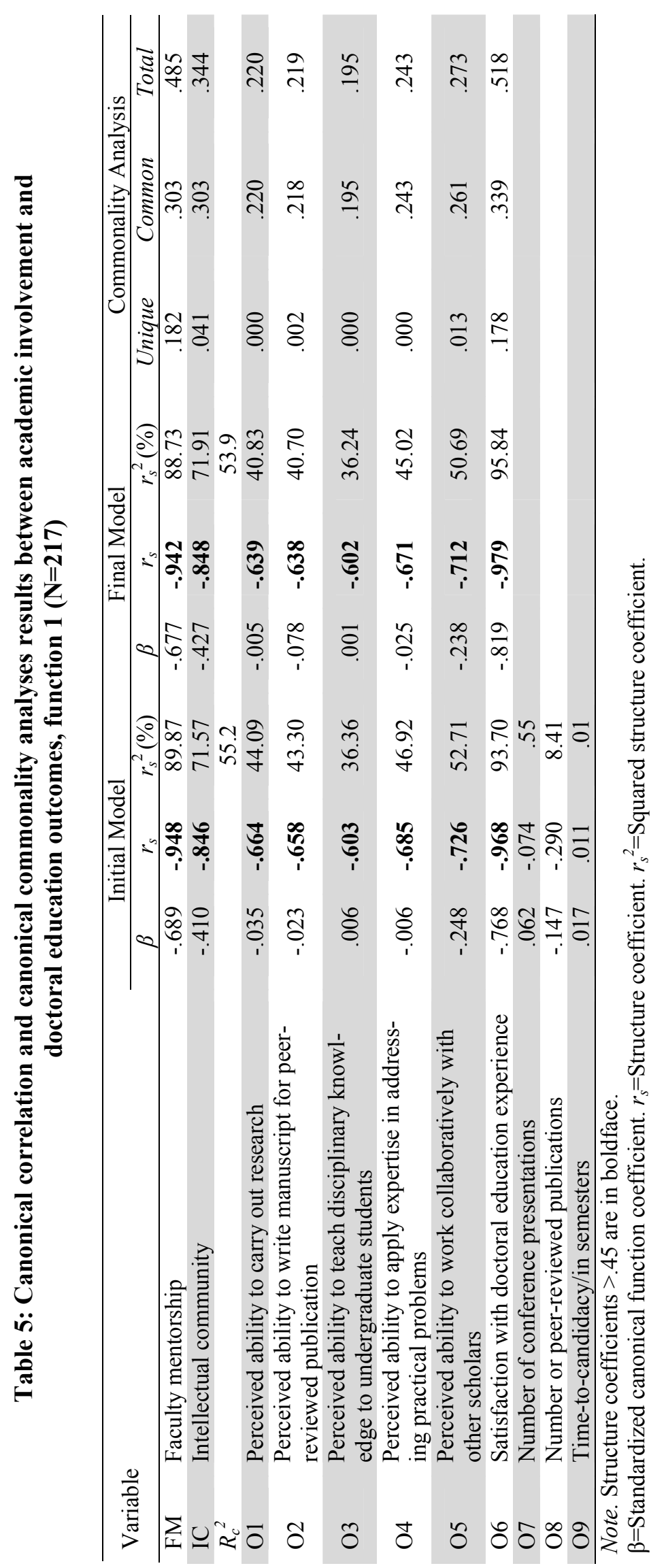


Within the outcome variable set, the variance unique to satisfaction (O6) and common to satisfaction and self-efficacy (O1 - O6) explains about $52.1 \%$ of the variance in the composite of outcome variable. The lack of unique effect attributable to self-efficacy indicates the variance selfefficacy contributes is also accounted for by satisfaction. These results suggest those who are more satisfied with their educational experience also tend to have greater sense of self-efficacy in undertaking various forms of scholarly work and/or vice versa. Participants' perceived ability to conduct research projects, write manuscripts for peer-reviewed publication, teach, solve practical problems, and work collaboratively with other scholars were all correlated with the degree to which they were satisfied with their doctoral education experience.

In summary, canonical correlation and commonality analyses concerning the multivariate predictive relationship between academic involvement and doctoral education outcomes suggest that perceived frequency of academic involvement, particularly frequent experience with faculty mentorship, are predictive of educational outcomes such as satisfaction with doctoral education experience and perceived self-efficacy in undertaking various forms of scholarly work. However a greater degree of academic involvement seems to have minimal predictive value for those more tangible doctoral educational outcomes such as scholarly productivity and degree progress.

Overall, participants reported experiencing all included dimensions of faculty mentorship and intellectual community during their doctoral study and felt each dimension to be important to their doctoral education experience. While perceived importance of each dimension was fairly uniform, there was greater variation in perceived frequency of experience. Perceived frequency of experiencing faculty mentorship and intellectual community was a strong predictor of doctoral education outcomes including overall satisfaction and perceived self-efficacy in the conduct of various forms of scholarship.

\section{Conclusions and Implications}

Perceived importance of academic involvement was relatively homogenous and highly rated, while the perceived frequency of academic involvement was less homogenous and more modestly rated. This suggests a discrepancy between what students value in doctoral education and what they perceive they have experienced in their programs. The value of academic involvement in predicting higher levels of program satisfaction and increased perceptions of self-efficacy to conduct scholarly work suggests that faculty mentorship and engagement in intellectual communities are educationally meritorious activities.

This conclusion lends support to Walker et al.'s (2008) suggestion that mentorship and intellectual community are crucial in doctoral education. In terms of student satisfaction and selfefficacy, doctoral students themselves add their voices to those who suggest that engagement between students, faculty, and the wider scholarly community is an important teaching and learning practice in doctoral education (Austin, 2002; Gardner \& Barnes, 2007; Golde, 2008; Kemp, Molloy, Pajic, \& Chapman, 2013; Walker et al., 2008). The extent to which faculty mentorship and intellectual community is available to students has bearing on doctoral students' development as scholars, their satisfaction with their doctoral program, and their perception of how appropriately they were prepared to undertake various forms of scholarly work.

One interesting finding that warrants further investigation is the substantial unique effect of mentorship in predicting doctoral education outcomes; intellectual community appears to offer little added benefit beyond what faculty mentoring contributes to predicting program satisfaction and self-efficacy. However intellectual community's small unique effect does not undermine its role in doctoral students' learning and development. The substantial common effect may reflect faculty mentorship occurring in formal and/or informal community settings. Faculty mentorship may itself serve as a source of intellectual community for doctoral students. Engagement in an intel- 
lectual community may likewise take the form of peer coaching that is similar to mentorship in many ways, if less structured and rarely formalized. The close conceptual ties between faculty mentorship and intellectual community are reflected in the results of this study. This relationship deserves further exploration in future research.

The findings of this study further reinforce the importance of the quality and quantity of facultystudent interaction on doctoral student socialization, degree completion, and satisfaction (Barnes \& Randall, 2011; Boyle, \& Boice, 1998; Council of Graduate Schools, 2009; Gardner, 2010; Girves \& Wemmerus, 1988; Golde, 2005, Lovitts, 2001). While a significant relationship between academic involvement and tangible, quantifiable outcomes such as scholarly products and degree progress was not identified in this study, such a relationship may yet exist. It may be that students present and publish papers with little help from mentors or intellectual community members, developing competence in this area independently and/or through mentorship received outside their doctoral programs. It is also possible that the candidacy stage is simply not a good time to measure this variable in this population, as students' research programs are still in early stages of development. Yet from the perspective of doctoral students, alumni, and employers, scholarly productivity is a central concern, and quantifiable outcomes as scholarly productivity and degree progress are used as benchmarks for doctoral programs in the State of Texas (Texas Higher Education Coordinating Board, 2009). Further investigation of the relationships between mentorship and intellectual community and such tangible doctoral education outcomes may well benefit from longitudinal study in order to identify trends that emerge over time.

The essence of this study's findings -that the degree to which students are satisfied with their education and perceive themselves to be prepared to undertake various forms of scholarship is related to the extent to which they experience faculty mentorship and intellectual communityimply that faculty mentorship and intellectual community are important in doctoral education. The potential for these practices to directly or indirectly affect outcomes such as capacity for independent scholarship (Gardner, 2008) and degree completion (Golde, 2005) holds promise, particularly in light of the current climate of higher education. Calls for greater effectiveness and efficiency in doctoral education specifically (Council of Graduate Schools, 2009) require that individual programs and faculty members pay close attention to their educational practices and the outcomes they engender. Furthermore, economic and social uncertainties call for innovative and creative solutions that knowledge workers are best capable of systematically addressing (Commission on the Future of Graduate Education in the US, 2010). Given these broader contexts and the findings of this study, the value of effective mentoring relationships between faculty and students as well as a lively community of scholars in program communities should be recognized and supported by all stakeholders, including students, faculty, and administrators.

First and foremost, students must be active agents in their own learning, recognizing the value of interacting with faculty and communities of scholars. Students must seek out or create learning opportunities, eliciting advice and feedback from faculty and peers. Students may serve as valuable apprentices to faculty, developing an effective and productive working relationship that serves both student and faculty. Mutually beneficial relationships between these stakeholders should be encouraged. Faculty, individually and/or collectively, can help students understand such opportunities and responsibilities by making goals, expectations, and assumptions clear to students from the very beginning of their doctoral programs.

At the heart of faculty mentoring of doctoral students is the intentionality (Austin, 2009; Walker et al., 2008) that provides students with focused, systematic, and explicit guidance and feedback about ways of conducting scholarship. While students have a responsibility to make themselves available, faculty should seek to draw students into scholarship as the opportunity arises to include early career scholars in their work. 
Faculty can also initiate and take part in a lively collegial community of scholars within their department or program, sharing experiences, resources, and opportunities to help advance doctoral students and other novice scholars in the program, and serving as invaluable source of expertise within the intellectual community. Quality and quantity of faculty-student interaction matters. Faculty must not take their role as mentors lightly, as students are keen observers of faculty behavior, which plays a significant role in their professional socialization (Austin, 2002).

An effective and productive community of scholars requires a supportive and collegial environment in which to thrive, which can be time-consuming, particularly for faculty. Although it is impractical to regulate or structure human relationships, certain conditions may promote the formation of such communities. Institutional and program administrators must endeavor to create policies and procedures supportive of teaching and learning practices that promote high quality doctoral education. Faculty workload policies have implications on faculty members' ability to provide quality educational experiences to students. Faculty reward mechanisms must therefore reflect the time-commitment required from faculty inside as well as outside of formal courses.

Finally, faculty mentorship should be evaluated for its effectiveness, and this evaluation should be given much more weight in not only workload assignments, but in tenure, promotion, and other faculty reward decisions. Similarly, student feedback on the quality of experiences with mentors should be elicited and employed to improve the overall educational experience. We understand that not all faculty are born mentors. Furthermore, although faculty have already experienced the mentoring relationship in their own experiences as a doctoral student, the effectiveness of those relationships and how their own experiences influence the relationships these faculty have with their own students is unknown. Therefore, professional development opportunities for faculty on advising and mentoring focused specifically on doctoral students might be worth the investment.

We know doctoral candidates in this study feel that all dimensions of mentorship and intellectual community are important, yet we do not know whether students' involvement or lack thereof was due to students' own choice or rather was due to absence of opportunities in their programs. Lacking a clear understanding of why some students more or less involved than others, judgments regarding program quality and effectiveness from students' perspectives can only offer a relatively incomplete picture. More qualitative and/or mixed research designs would aid in furthering our understanding of these phenomena, as would more particularistic study of specific doctoral education contexts.

This study focused on doctoral candidates' experiences and perceptions. Participants were students at the last stage of their programs of study - conducting independent research, in some cases for the very first time. Some had not yet begun, and others may never complete this stage (Bowen \& Rudenstine, 1992; Lovitts, 2001). Those who have completed independent research may have very different perceptions and experiences, as their doctoral education experiences would reflect the entire spectrum of their program of study. In an ideal context, sampling from those who have completed their degree programs may provide a more useful glimpse at doctoral education from students' perspectives. Similarly, longitudinal studies tracking graduates' career trajectories, scholarly productivity, and their sense of self-efficacy would shed useful light on how the doctoral education experiences affect ongoing development following graduation.

Given the role that academic involvement plays in doctoral education, exploring and identifying factors associated with student involvement will aid in clarifying expectations of students. For example, faculty perceive certain student characteristics including intelligence, independence, self-direction, and creativity (Gardner, 2009) as important for doctoral students to succeed. These characteristics may therefore have a bearing on students' doctoral educational experiences. Exam- 
ining the extent to which these characteristics predict academic involvement may prove useful for informing practice and policy related to doctoral education.

\section{References}

Altbach, P. G. (2004). Doctoral education: Present realities and future trends. College and University, $80(2), 3-10$.

Astin, A. W. (1984). Student involvement: A developmental theory for higher education. Journal of College Student Development, 25, 297-308.

Astin, A. W. (1993). What matters in college? Four critical years revisited. San Francisco, CA: JosseyBass.

Austin, A. E. (2002). Preparing the next generation of faculty: Graduate school as socialization to the academic career. Journal of Higher Education, 73(1), 94-122.

Austin, A. E. (2009). Cognitive apprenticeship theory and its implications for doctoral education: A case example from a doctoral program in higher and adult education. International Journal for Academic Development, 14(3), 173-183.

Austin, A. E., \& McDaniels, M. (2006). Using doctoral education to prepare faculty to work within Boyer's four domains of scholarship. New Directions for Institutional Research, 129, 51-65. doi:10.1002/ir.171

Baltes, B., Hoffman-Kipp, P., Lynn, L., \& Weltzer-Ward, L. (2010). Students research self-efficacy during online doctoral research courses. Contemporary Issues in Education Research, 3(3), 51-57.

Bandura, A. (1997). Self-efficacy: The exercise of control. New York, NY: Freeman.

Barnes, B. J., \& Randall, J. (2011). Doctoral student satisfaction: An examination of disciplinary, enrollment, and institutional differences. Research in Higher Education, 53(1), 47-75. doi: 10.1007/s11162011-9225-4

Bowen, W. G., \& Rudenstine, N. L. (1992). In pursuit of the PhD. Princeton, NJ: Princeton University Press.

Boyle, P., \& Boice, B. (1998). Best practices for enculturation: Collegiality, mentoring, and structure. New Directions for Higher Education, 101, 87-94.

Brown, J. S., Collins, A., \& Duguid, P. (1989). Situated cognition and the culture of learning. Educational Researcher, 18(1), 32-42.

Carnegie Foundation for the Advancement of Teaching. (2010). The Carnegie classification of institutions of higher education. Retrieved from http://classifications.carnegiefoundation.org/

Cattell, R. B. (1966). The scree test for the number of factors. Multivariate Behavioral Research, 1, 245276.

Commission on the Future of Graduate Education in the US. (2010). The path forward. Retrieved from http://www.fgereport.org/index.html

Council of Graduate Schools. (2005). The Doctor of Philosophy degree: A policy statement. Washington, DC: Author.

Council of Graduate Schools. (2009). Ph.D. completion and attrition: Findings from exit surveys of Ph.D. completers. Washington, DC: Author.

Gardner, S. K. (2008). "What's too much and what's too little?" The process of becoming an independent researcher in doctoral education. Journal of Higher Education, 79(3), 326-350. doi:10.1353/jhe.0.0007

Gardner, S. K. (2009). Conceptualizing success in doctoral education: Perspectives of faculty in seven disciplines. Review of Higher Education, 32(3), 383-406. 
Gardner, S. K. (2010). Contrasting the socialization experiences of doctoral students in high- and lowcompleting departments: A qualitative analysis of disciplinary contexts at one institution. Journal of Higher Education, 81(1), 61-81.

Gardner, S. K., \& Barnes, B. J. (2007). Graduate student involvement: Socialization for the professional role. Journal of College Student Development, 48(4), 369-387. doi: 10.1353/csd.2007.0036

Girves, J. E., \& Wemmerus, V. (1988). Developing models of graduate student degree progress. Journal of Higher Education, 59(2), 163-189.

Golde, C. M. (2005). The role of the department and discipline in doctoral student attrition: Lessons from four departments. Journal of Higher Education, 76(6), 669-700.

Golde, C. M. (2008). Applying lessons from professional education to the preparation of the professoriate. New Directions for Teaching and Learning, 113, 17-25. doi: 10.1002/tl

Golde, C. M., \& Dore, T. M. (2001). At cross purposes: What the experiences of today's doctoral students reveal about doctoral education. Retrieved from http://www.phd-survey.org/

Haworth, J. G., \& Bair, C. R. (2000, November). Learning experiences that make a difference: Findings from a national study of doctoral education in the professions. Paper session presented at the meeting of the Association for the Study of Higher Education, Sacramento, CA.

Henson, R. K. (1999). Multivariate normality: What is it and how is it assessed? In B. Thompson (Ed.), Advances in social science methodology (Vol. 5, pp. 193-211). Stamford, CT: JAI.

Henson, R. K. (2001). Understanding internal consistency reliability estimates: A conceptual primer on coefficient alpha. Measurement and Evaluation in Counseling and Development, 34(3), 177-189.

Henson, R. K., \& Roberts, J. K. (2006). Use of exploratory factor analysis in published research: Common errors and some comment on improved practice. Educational and Psychological Measurement, 66(3), 393-416. doi: 10.1177/0013164405282485

Kaiser, H. F. (1960). The application on electronic computers to factor analysis. Educational and Psychological Measurement, 20, 141-151.

Kemp, M. W., Molloy, T. J., Pajic, M., \& Chapman, E. (2013). Peer relationships and the biomedical doctorate: A key component of the contemporary learning environment. Journal of Higher Education Policy and Management, 35(4), 370-85.

Lambie, G. W., Hayes, B. G., Griffith, C., Limberg, D., \& Mullen, P. R. (2013). An exploratory investigation of the research self-efficacy, interest in research, and research knowledge of $\mathrm{PhD}$ in education students. Innovative Higher Education, 39(2).

Loo, R. (2001). Motivational orientations toward work: An evaluation of the work preference inventory. Measurement and Evaluation in Counseling and Development, 33(4), 222-233.

Lovitts, B. E. (2001). Leaving the ivory tower: The causes and consequences of departure from doctoral study. Lanham, MD: Rowman \& Littlefield.

Lovitts, B. E. (2005). Being a good course-taker is not enough: A theoretical perspective on the transition to independent research. Studies in Higher Education, 30(2), 137-154.

Maher, M. A., Ford, M. E., \& Thompson, C. M. (2004). Degree progress of women doctoral students: Factors that constrain, facilitate, and differentiate. Review of Higher Education, 27(3), 385-408.

Nimon, K., Henson, R. K., \& Gates, M. (2010). Revisiting interpretation of canonical correlation analysis: A tutorial and demonstration of canonical commonality analysis. Multivariate Behavioral Research, 45(4), 702-724. doi: 10.1080/00273171.2010.498293

Nyquist, J. D. (2002). The PhD: A tapestry of change for the 21st century. Change, 34(6), 12-20.

Nyquist, J. D., \& Woodford, B. J. (2000). Re-Envisioning the Ph.D.: What concerns do we have? Seattle, WA: University of Washington, Center for Instructional Development and Research. 
O'Meara, K., Knudsen, K., \& Jones, J. (2013). The role of emotional competencies in faculty-doctoral student relationships. Review of Higher Education, 36(3), 315-47.

Pascarella, E. T., \& Terenzini, P. T. (2005). How college affects students: A third decade of research. San Francisco: Jossey Bass.

Schniederjans, M. J. (2007). A proposed Ph.D. student bill of rights. International Journal of Doctoral Studies, 2, 1-8. Retrieved from http://www.ijds.org/Volume2/IJDSv2p001-008Schniederjans22.pdf

Sherry, A., \& Henson, R. K. (2005). Conducting and interpreting canonical correlation analysis in personality research: A user-friendly primer. Journal of Personality Assessment, 84, 37-48. doi: 0.1207/s15327752jpa8401_09

Shulman, L. S. (2008). Foreword. In G. E. Walker, C. M. Golde, L. Jones, A. C. Bueschel, \& P. Hutchings (Eds.), The formation of scholars (pp. ix-xiii). San Francisco, CA: Jossey Bass.

Shulman, L. S., \& Hutchings, P. (1998). About the scholarship of teaching and learning: The Pew Scholars' National Fellowship Program. Menlo Park: CA: The Carnegie Foundation for the Advancement of Teaching.

Texas Higher Education Coordinating Board. (2009). 18 characteristics of Texas public doctoral programs for 2010. Retrieved from http://www.thecb.state.tx.us/index.cfm?objectid=979F4DE2-9BD9-EB3173EE814672699D50

Tinto, V. (1993). Leaving college: Rethinking causes and cures of student attrition (2nd ed.). Chicago, IL: The University of Chicago Press.

Thompson, B. (1990). MULTINOR: A FORTRAN program that assist in evaluating multivariate normality. Educational and Psychological Measurement, 50, 845-848.

Thompson, B. (1991). A primer on the logic and use of canonical correlation analysis. Measurement and Evaluation in Counseling and Development, 24(2), 80-93.

Thompson, B. (1993). Calculation of standardized, non-centered factor scores: An alternative to conventional factor scores. Perceptual and Motor Skills, 77, 1128-1130.

Thompson, B. (2004). Exploratory and confirmatory factor analysis: Understanding concepts and applications. Washington, DC: American Psychological Association.

Velicer, W. F. (1976). Determining the number of components from the matrix of partial correlations. Psychometrika, 41, 321-327.

Walker, G. E. (2008). Doctoral education in the United States of America. Higher Education in Europe, $33(1), 35-43$.

Walker, G. E., Golde, C. M., Jones, L., Bueschel, A.C., \& Hutchins, P. (2008). The formation of scholars: Rethinking doctoral education for the twenty-first century. San Francisco, CA: Jossey-Bass.

Wenger, E. (1996). Communities of practice: The social fabric of a learning organization. The Healthcare Forum Journal, 39, 20-25. 


\section{Biographies}

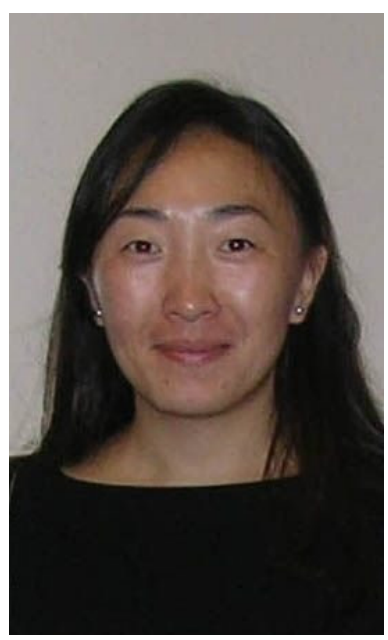

Baaska Anderson is a doctoral tutor in the University of Liverpool's doctoral program in Higher Education. She is also an independent consultant in areas of instrument development and validation, research design, and statistical analyses. Her research interests include efficacy of doctoral education and learning technologies in graduate education.

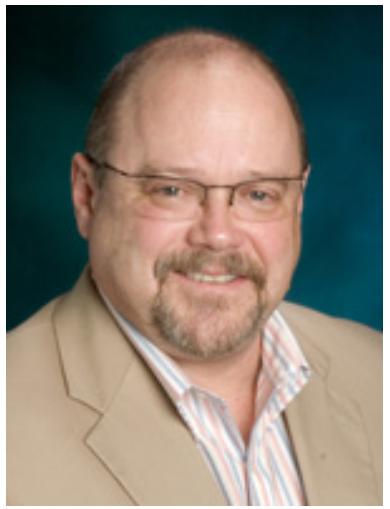

Marc Cutright is an associate professor and the director of the Center for Higher Education at the University of North Texas. Currently, he is a Fulbright Scholar in East Africa. He has extensive experience mentoring doctoral students. His primary research interests include international higher education, first-year experience, and transfer issues.

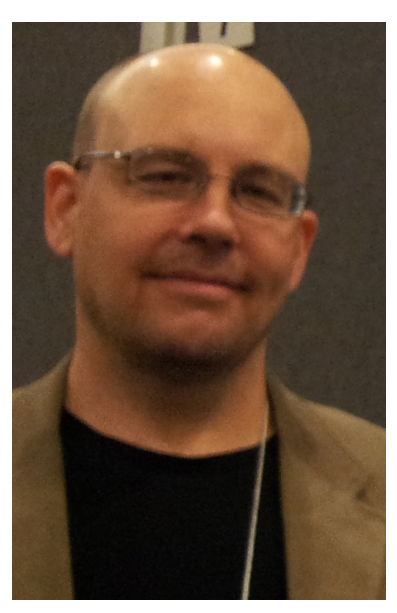

Stoerm Anderson is a core faculty and research coordinator at Walden University. He has extensive experience mentoring graduate students. His primary research interest focuses on doctoral education in the professions. 